\title{
Superoxide overproduction and kidney fibrosis: a new animal model
}

\author{
Produção aumentada de superóxido e fibrose renal: novo modelo animal
}

\author{
Nadia Karina Guimarães-Souza ${ }^{1}$, Liliya Marsovna Yamaleyeva², Baisong Lu², \\ Ana Claudia Mallet de Souza Ramos ${ }^{1}$, Colin Edward Bishop ${ }^{2}$, Karl Erik Andersson ${ }^{2}$
}

\begin{abstract}
Objective: To establish whether the mutation in the Immp2L gene induces renal fibrosis and whether aging exacerbates renal morphology in mice. Methods: Female mutant mice with mutation in the inner mitochondrial membrane peptidase 2-like protein at 3 and 18 months of age were used. Renal fibrosis was analyzed using classic fibrosis score, Masson's trichrome staining, and analysis of profibrotic markers using real time polymerase chain reaction (superoxide dismutase 1, metalloproteinase-9, erythropoietin, transforming growth factor beta), and immunostaining (fibroblasts and Type IV collagen). Oxidative stress markers were determined by immunohistochemistry. The number of renal apoptotic cells was determined. Renal function was estimated by serum creatinine. Results: Young mutant mice had significantly more glomerulosclerosis than age-matched mice $(p=0.034)$. Mutant mice had more tubular casts $(p=0.025)$, collagen deposition $(p=0.019)$, and collagen type IV expression $(p<0.001)$. Superoxide dismutase 1 expression was significantly higher in young mutants $(p=0.038)$. Old mutants exhibited significantly higher expression of the fibroblast marker and macrophage marker $(p=0.007$ and $p=0.012$, respectively). The real time polymerase chain reaction of metalloproteinase- 9 and erythropoietin were enhanced 2.5 - and 6-fold, respectively, in old mutants. Serum creatinine was significantly higher in old mutants $(p<0.001)$. Conclusion: This mutation altered renal architecture by increasing the deposition of extracellular matrix, oxidative stress, and inflammation, suggesting a protective role of Immp2L against renal fibrosis.
\end{abstract}

Keywords: Renal insufficiency, chronic; Inflammation; Mice, transgenic; Models, animal; Oxidative stress

\section{RESUMO}

Objetivo: Estabelecer se a mutação no gene Immp2L induz à fibrose renal e se 0 envelhecimento exacerba a morfologia renal em camundongos. Métodos: Foram usadas fêmeas de camundongos mutantes para proteína semelhante à peptidase 2 da camada interna da mitocôndria, com 3 e 18 meses de idade. Para analisar a fibrose renal, foram usados 0 escore clássico de fibrose, a coloração com tricrômio de Masson, e a análise de marcadores profibróticos, por meio da reação em cadeia de polimerase em tempo real (superóxido dismutase 1, metalonoproteinase-9, eritropoietina e fator transformador de crescimento beta), e a imunocoloração (fibroblastos e colágeno IV). Marcadores de estresse oxidativo foram determinados por imunohistoquímica. 0 número de células apoptóticas renais foi analisado. A função renal foi estimada por creatinina sérica. Resultados: Camundongos mutantes jovens apresentaram glomeruloesclerose em quantidade significativamente maior que animais da mesma idade $(p=0,034)$. Os mutantes mostraram maior formação de cilindros tubulares $(p=0,025)$, deposição de colágeno $(p=0,019)$ e maior expressão de colágeno do tipo IV $(p<0,001)$. A expressão de superóxido dismutase 1 foi maior em mutantes jovens $(p=0,038)$. Mutantes idosas exibiram maior expressão dos marcadores de fibroblastos e macrófagos ( $p=0,007$ e $p=0,012$, respectivamente). As reações da cadeia de polimerase em tempo real da metalanoproteinase-9 e da eritropoietina estavam aumentadas em 2,5 e 6 vezes, respectivamente, em mutantes idosas. A creatinina sérica foi significantemente maior em animais idosos mutantes $(p<0,001)$. Conclusão: Essa mutação alterou a arquitetura renal pelo aumento da deposição de matriz extracelular, estresse oxidativo e inflamação, sugerindo papel de proteção de $1 \mathrm{mmp} 2 \mathrm{~L}$ contra a fibrose renal.

Descritores: Insuficiência renal crônica; Inflamação; Camundongos transgênicos; Modelos animais; Estresse oxidativo

\footnotetext{
${ }^{1}$ Hospital Israelita Albert Einstein, São Paulo, SP, Brazil.

${ }^{2}$ Wake Forest Institute for Regenerative Medicine, Winston-Salem, NC, USA.

Corresponding author: Nádia Karina Guimarães-Souza - Instituto de Ensino e Pesquisa, Centro de Diálise - Avenida Albert Einstein, 627/701, 2ss floor - Morumbi - Zip code: 05651-901 - São Paulo, SP, Brazil - Phone: (55 11) 2151-3090 - E-mail: nadiakgs@einstein.br

Received on: May 16, 2014 - Accepted on: Jan 6, 2015

Conflict of interest: none.

DOI: 10.1590/\$1679-45082015A03179
} 


\section{INTRODUCTION}

Renal fibrosis is the major determinant of chronic kidney disease progression and typically results from chronic inflammation. Despite having different etiologies and clinical manifestations, most chronic fibrotic disorders have in common a persistent production of growth factors, proteolytic enzymes, angiogenesis factors, fibrogenic cytokines, and reactive oxygen species (ROS). These conditions stimulate deposition of extracellular matrix that progressively destroys the organ's architecture and consequently its function. ${ }^{(1)}$ Recently, ROS have been associated with kidney fibrosis in different diseases including chronic allograft nephropathy following transplantation, ${ }^{(2)}$ and diabetic renal damage. ${ }^{(3)}$ Furthermore, ROS have been shown to be important mediators of the adverse effects of the renin-angiotensin-aldosterone system (RAAS) in renal and vascular tissue. ${ }^{(4)}$

ROS are normal products of the aerobic metabolism and include, for example, superoxide anion $\left(\mathrm{O}_{2}^{-}\right)$, hydrogen peroxide $\left(\mathrm{H}_{2} \mathrm{O}_{2}\right)$, peroxynitrite $\left(\mathrm{ONOO}^{-}\right)$, and the hydroxyl radical $(-\mathrm{OH})$. Superoxide dismutase (SOD) is the main antioxidant enzyme for superoxide removal. In mammals, three isoforms of SOD have been described: cytoplasmic CuZnSOD (SOD-1), mitochondrial MnSOD (SOD-2), and extracellular CuZnSOD (SOD-3). When the production of ROS overcomes the antioxidant defense mechanisms, the result is oxidative stress. ROS can react with DNA, proteins, and lipids leading to, respectively, breakdown of DNA strands, protein oxidation, and lipid peroxidation. ${ }^{(5)}$ By covalently modifying membraneassociated proteins, the membrane lipid peroxidation product 4-hydroxynonenal (4-HNE) may play a role in oxidative stress damage. ${ }^{(6)}$

Mitochondria are the primary source of ROS, and it is well known that changes in mitochondrial function may lead to overproduction of superoxide. Thus, Immp2L mutant mice, which have a deficiency of the inner mitochondrial membrane peptidase 2-like protein (Immp2L) and present an abnormal signal peptide sequence processing of mitochondrial proteins cytochrome $\mathrm{c}$ (CYC1) and glycerol-3-phosphate dehydrogenase (GPD2), exhibit overproduction of superoxide ions and high levels of ATP, probably due to a high mitochondrial respiration rate. Mitochondrial protein $\mathrm{CYC1}$ in the kidney of these mutant mice has a higher molecular weight compared to wild type controls. ${ }^{(7)}$ The abnormal size of this peptide is consistent with a loss of activity of Immp2L affecting the cleavage of the intermembrane space. ${ }^{(8)}$ These mutant mice may be an interesting model to study superoxide-induced kidney effects without interfering comorbidities or secondary factors.

\section{OBJECTIVE}

To establish whether the mutation in the Immp2L gene induces renal fibrosis, inflammation, and oxidative stress, and whether aging exacerbates renal morphology in these animals, since aging is associated with changes in renal pathology and an increase in oxidative stress.

\section{METHODS}

\section{Animals}

Animals were bred and housed in the animal facilities of Wake Forest University Health Sciences. Experiments were approved by the local Animal Care and Use Committee (ACUC) and conducted according to the National Research Council publication Guide for Care and Use of Laboratory Animal (A08-071).

The mutant mouse, the Immp2L Tg (Tyr) 979 Ove, was produced with a transgenic insertion mutagenesis strategy. By injecting a tyrosinase minigene into fertilized eggs of Albino FVB mice and screening for offspring with phenotypes in the reproductive system, a mutant line with impaired fertility in both sexes was obtained. The genomic lesion of the mutant line was mapped to chromosome 12, disrupting the Immp2L gene. ${ }^{(7)}$ Female mutants were age-matched with female wild-type animals. For the purpose of this study, 3 months of age were considered young and animals of 18 months of age were considered old ( $n=4$ in each group).

The study was conducted from September 2009 to December 2012. All animal procedures, as blood, urine, and histological analyses, were made at the Wake Forest Institute for Regenerative Medicine.

\section{Morphometric analysis}

After fixation with $10 \%$ neutral buffered formalin, the kidney specimens were embedded in paraffin and sectioned at $4 \mu \mathrm{m}$ thickness. Glomerular injury was assessed according to Raji in hematoxylin and eosin stained sections ${ }^{(9)}$ in 20 randomly chosen fields from cortex and medulla using 4 animals per group under 200x magnification. Briefly, the severity of the lesion was graded from zero to $4+$ according to the percentage of glomerular involvement. Thus, a $1+$ lesion represented an involvement of $25 \%$ of the individual glomerulus, 
while a $4+$ lesion indicated that $100 \%$ of the glomerulus was involved. An injury score was then obtained by multiplying the degree of damage (zero to $4+$ ) by the percentage of the glomeruli with the same degree of injury, which is, increase in mesangial matrix material or glomerulosclerosis. Tubular casts were counted in the same fields for all 20 chosen fields ( $n=4$ per group). Tubular atrophy was considered as the dilation of tubules and areas in which normal tissue was substituted by fibrosis in the same chosen fields, and was quantified by the computerized morphometric software (AxioVision).

\section{Masson's trichrome staining}

Extracellular matrix deposition was measured using Masson's trichrome staining. Twenty randomly chosen fields of cortex and medulla were analyzed ( $n=4$ animals per group) under 200x magnification. The collagen-toparenchyma ratio was calculated in order to compare interstitial renal fibrosis in the four different groups.

\section{Immunostaining}

Four $-\mu \mathrm{m}$ paraffin sections were treated with antigen retrieval procedure in microwave, using Antigen Retrieval Solution Ready-to-Use (DAKO, Carpinteria, CA, United States). For cytoplasm proteins, cells were permeabilized with $0.1 \%$ Triton (Sigma, St. Louis, MA, United States) in PBS, for three minutes, rinsed in PBS, and blocked with $10 \%$ serum (FBS; Gibco ${ }^{\mathrm{TM}}$ Invitrogen, Carlsbad, CA, United States) for 30 minutes and protein block serum free solution, for 1 hour. Tissue was incubated with primary antibodies (SOD-1 1:500; type IV collagen 1:500; S100A4 1:50, all from Abcam Inc., Cambridge, MA, United States; CD68 1:200 Chemicon, CA; and 4-HNE 1:15,000 from Calbiochem, San Diego, CA, United States) for 1 hour, at room temperature, and biotinylated secondary antibodies for 30 minutes.

For assessment of SOD-1, S100A4, and type IV collagen, 20 random fields were analyzed in the kidney of each animal ( $n=4$ per group) under 20x magnification. The positive areas were quantified by computerized morphometric analysis with AxioVision software. The final score for each animal represents the average of the 20 fields. For assessment of CD68, 20 random fields were analyzed for each animal (4 per group) under 20-x magnification. Positive cells were counted and compared among the groups. For evaluation of 4-HNE, 20 random fields were analyzed for each animal $(\mathrm{n}=4$ per group) under $20 \mathrm{x}$ magnification. Positive tubules were considered when three or more cells were positive in the tubule. A percentage of positive tubules to total tubules was determined and compared among the groups.

\section{Identification of apoptotic cells}

Apoptotic cells in paraffin-embedded sections were visualized by terminal deoxynucleotidyl transferase (TdT) using TACS TdT kit (R\&D Systems, Minneapolis, MN, United States) with immunoperoxidase visualization according to the manufacture's protocol. Twenty random fields of sections from each animal were analyzed; positive cells were counted and compared among the groups using number of cells per field as unit.

\section{Microscope specifications}

We used Leica DM 4000B (Leica Mic Leica Microsystems, Bannockburn, IL, United States) microscope. Room temperature was $22^{\circ} \mathrm{C}$; imaging medium was Immersol ${ }^{\mathrm{TM}}$ 518F for fluorescent microscopy (Zeiss AG, Oberkochen, Germany). Images were performed in 20x HC PL FLUOTAR (NA 0.5) and 40x dry HCX PL FLUOTAR (NA 0.75). The camera used for all images was QImaging, model Retiga-2000RV (Surrey, BC, Canada), and the acquisition software was Image Pro 6.3 (Media Cybernetics, Bethesda, MD, United States).

\section{Quantitative real time polymerase chain reaction}

RNA was isolated from kidney tissues ( $n=4$ per group). RNeasy Mini kit from QIAGEN was used for RNA extraction. RNA integrity and quantity were determined with spectrophotometry. Equal amounts of total RNA were reverse-transcribed with reverse transcriptase (Gibco $^{\mathrm{TM}}$ Invitrogen, Carlsbad, CA, United States). Quantitative polymerase chain reaction (PCR) for SOD-1, transforming growth factor beta (TGF- 3 ), metalloproteinase-9 (MMP-9) and erythropoietin (EPO) were performed using TaqMan Gene Expression Assays with primer probes sets purchased from Applied Biosystems. Reactions were performed in triplicate. Quantification of messenger RNA (mRNA) was performed by the Delta-Delta CT method. Results were normalized to GAPDH and expressed as fold change in mutants compared to old wild type.

\section{Renal function}

To determine the serum creatinine, $30 \mu \mathrm{L}$ of blood was taken by cardiac aspiration when animals were 
euthanized ( $\mathrm{n}=4$ in each group: old mutants and old wild type animals). Creatinine was measured using QuantiChrom ${ }^{\mathrm{TM}}$ Creatinine Assay Kit, according to the manufacturer's instructions.

\section{Statistical analysis}

Data were expressed as means \pm standard deviation. Statistical analysis was performed using SigmaStat software. For comparison of two groups Student's $t$ test or Mann-Whitney Rank Sum test was performed. Differences among all groups were carried out using one-way analysis of variance (one-way ANOVA). We considered $\mathrm{p}<0.05$ statistically significant.

\section{RESULTS}

Female mutant Immp2L mice at 3 and 18 months of age were compared to their respective wild-type counterparts. Young mutants were also compared to older mutants to assess the effects of aging in Immp2L mice on renal fibrosis, oxidative stress, and inflammation. No differences were found in animal's body weight (young wild type: $31.77 \pm 7.92 \mathrm{~g}$; young mutant: $26.67 \pm 3.42 \mathrm{~g}$; old wild type: $35.02 \pm 7.19 \mathrm{~g}$ and old mutant: $37.1 \pm 8.57 \mathrm{~g}$ ), or in the kidney weights (young wild type: $0.41 \pm 0.04$; young mutant: $0.34 \pm 0.06$; old wild: $0.39 \pm 0.06$ and old mutant: $0.32 \pm 0.07)$. The ratio of kidney-to-body weight was also similar among the groups.

The alterations in renal morphology were characterized using indices of renal fibrosis in hematoxylin and eosin stained kidney sections. Glomerulosclerosis was graded zero to 4, and a total score was used to compare the groups. Young mutants had significantly increased glomerulosclerosis compared to young wild type animals $(\mathrm{p}=0.034)$; however, old mutants and old wild type mice exhibited similar scores (Figure 1A, and Figures $2 \mathrm{~A}$ to $2 \mathrm{D}$ ). Tubular casts were more prevalent in mutant animals regardless of age when compared to wild

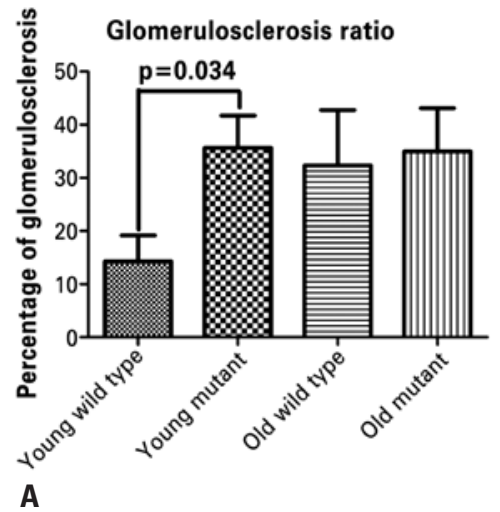

Total collagen deposition

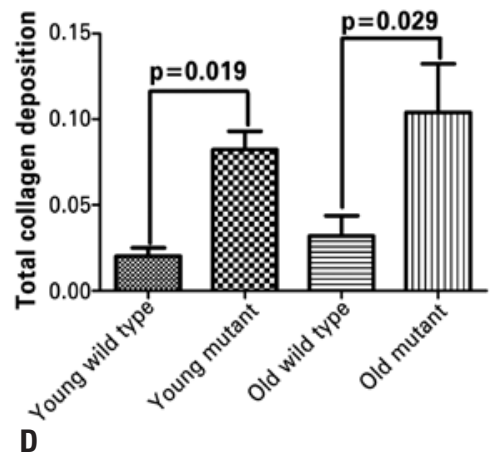

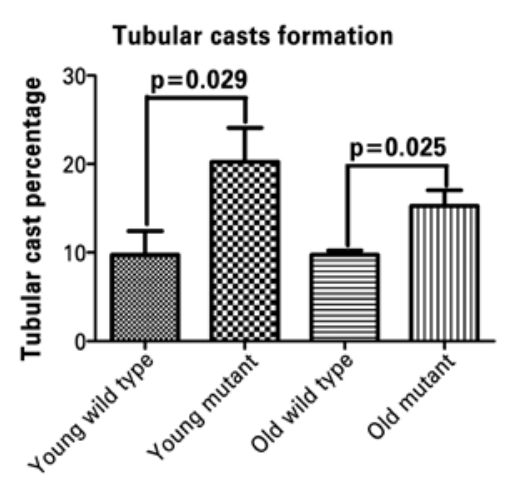

B

Collagen type IV expression

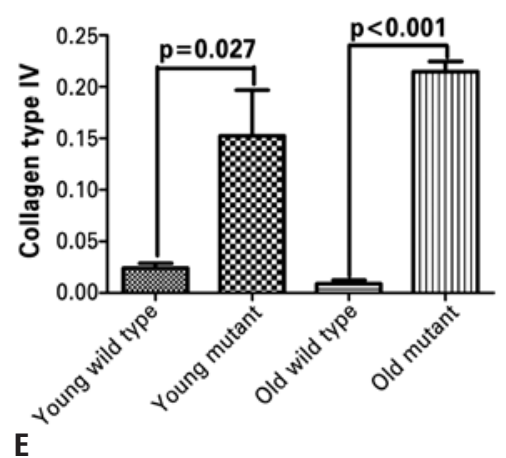

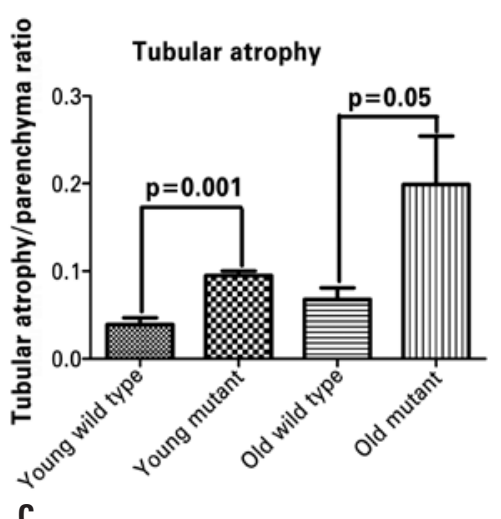

C

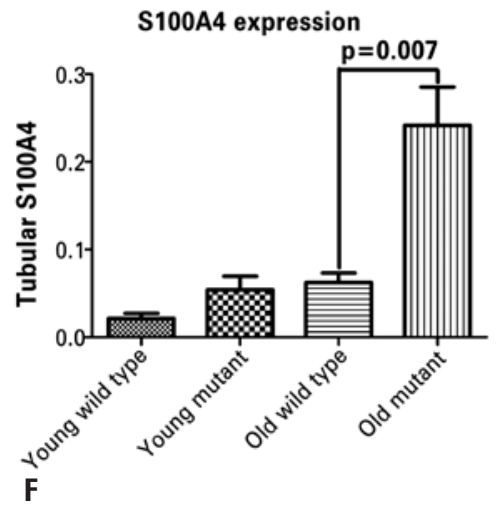

Figure 1. Analysis of renal fibrosis in the Immpl2 mutant mice and wild type controls. Glomerulosclerosis score (A), tubular cast formation (B), and tubular atrophy (C) were assessed using hematoxylin and eosin staining. Young mutant animals had significantly higher scores than the age-matched controls in A, B, and C while old mutants had more tubular casts and tubular atrophy than age-matched controls. The collagen deposition (D) was assessed by Masson's trichrome staining. The collagen deposition was significantly higher in mutants, regardless of age. Type IV collagen (E) was measured using immunostaining and was higher in mutants. The epithelial-tomesenchymal transition was analyzed using S100A4 staining (F). Old mutant mice exhibited significantly higher expression of fibroblast marker in tubular epithelial cells, representing the epithelial-to-mesenchymal transition 

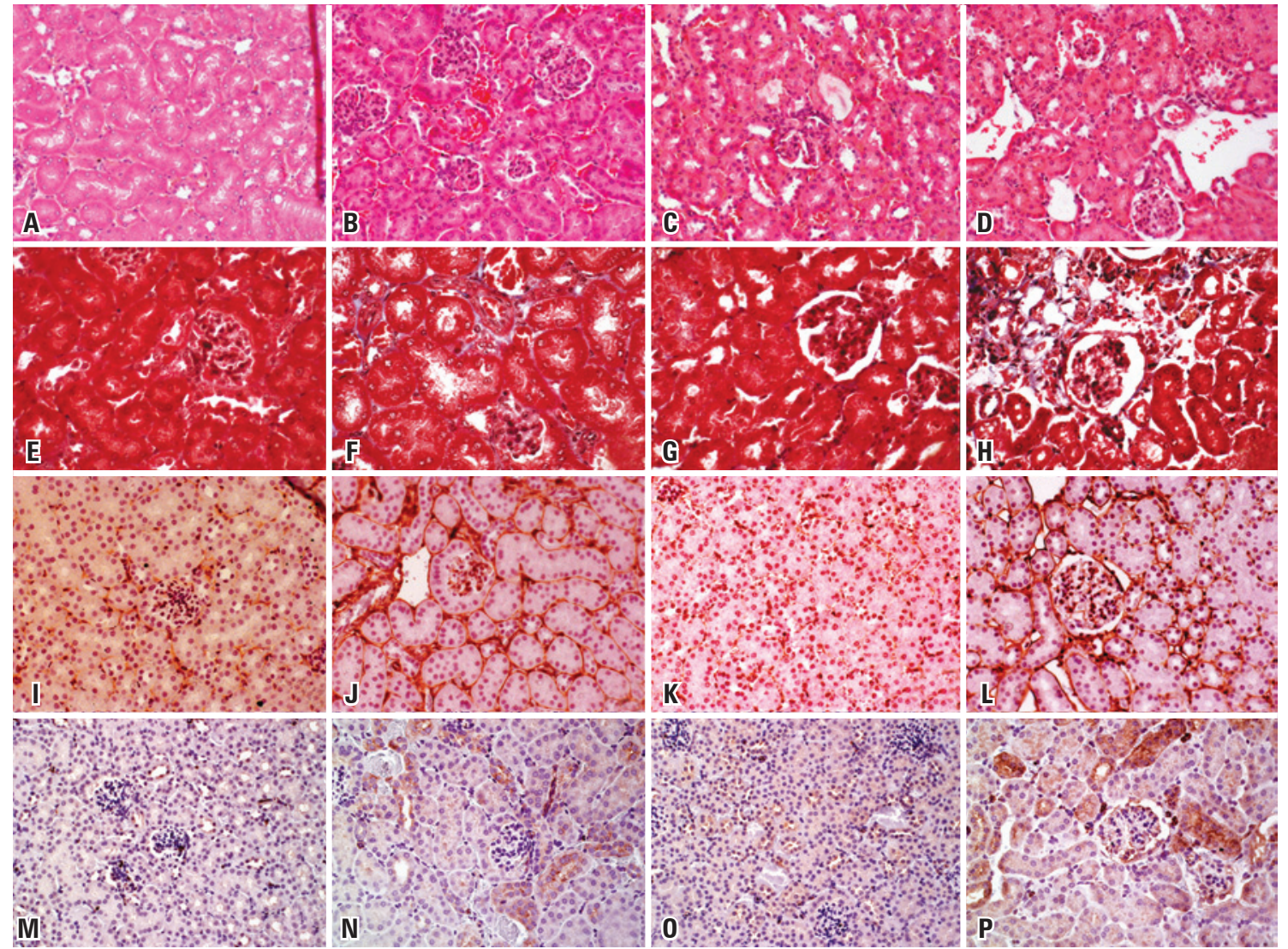

Figure 2. Representative pictures of hematoxylin and eosin, Masson's trichrome staining, and profibrotic markers (collagen IV and S100A4) in the kidney of Immpl2 mice and wild type controls. Representative hematoxylin and eosin staining is shown in the upper part of the panel. (A) Young wild type animals. In young mutants (B), sclerotic glomeruli and some tubular atrophy are seen. Old wild type (C) showed some tubular atrophy and tubular cast formation. Old mutants (D) exhibited tubular atrophy and glomerulosclerosis. E to $\mathrm{H}$ represent young wild type, young mutant, old wild type, and old mutant mice respectively. Masson's trichrome staining was used to measure total collagen/parenchyma ratio. Blue represents extracellular matrix and red, the parenchyma. Partial sclerosis of glomeruli is visible in $\mathrm{G}$ and $\mathrm{H}$. Old mutant mice had a distortion of the organ architecture with substitution of tubular structures by collagen. Pictures I to $L$ represent young wild type, young mutant, old wild type, and old mutant, respectively. Type IV collagen is shown by brown staining. Mutant mice had more type IV collagen deposition than age-matched controls. M to P represent young wild type, young mutant, old wild type, and old mutant, respectively. The brown staining corresponds to epithelial cells positive for S100A4, a fibroblast marker. All pictures were obtained in 20x magnification

type controls. Thus, young and old mutants differed significantly from young and old wild type mice $(p=0.029$ and $p=0.025)$. (Figure $1 B$, and Figures $2 A$ to 2D). Tubular atrophy, represented by thick irregular tubular basement membranes with decreased diameter of tubules and increase in the interstitial space, was significantly more pronounced in mutant than in wild type mice, regardless of age $(p=0.001$ and $p=0.005$ for young and old mutant mice, respectively). Old mutants had significantly more tubular atrophy compared to young mutants $(\mathrm{p}=0.019)$, and to young controls $(p=0.029)$. No differences were found between young and old wild type controls (Figure 1C, and Figures $2 \mathrm{~A}$ to $2 \mathrm{D}$ ). Young mutant mice had a significantly higher collagen-to-parenchyma ratio than aged matched controls as evaluated by Masson's trichrome staining $(\mathrm{p}=0.019)$. Old mutants had significantly more collagen deposition compared to old wild type mice $(\mathrm{p}=0.029)$. Young mutants exhibited more collagen deposition than old wild type controls $(p=0.009)$ (Figure 1D, and Figures $2 \mathrm{E}$ to $2 \mathrm{H}$ ). In addition, collagen type IV immunostaining was significantly higher in young mutants compared to age-matched wild type mice $(p=0.027)$. Old mutants and aged-matched wild type controls were also significantly different $(p<0.001)$. Young mutant mice had a higher expression of collagen type IV than old wild type animals $(\mathrm{p}=0.004)$ (Figure $1 \mathrm{E}$, and Figures $2 \mathrm{I}$ to $2 \mathrm{~L}$ ).

Epithelial-to-mesenchymal transition was established by the analysis of fibroblast marker S100A4 only when the stain was present in tubular structures. The expression of S100A4 in young mutant animals was not 
different from that of young wild type mice $(\mathrm{p}=0.377)$. However, old mutant animals exhibited significantly higher S100A4 expression compared to aged matched wild type $(\mathrm{p}<0.001)$, young mutants $(\mathrm{p}<0.001)$, and young wild type mice $(\mathrm{p}=0.007)$ (Figure $1 \mathrm{~F}$, and Figures $2 \mathrm{M}$ to $2 \mathrm{P})$.

SOD-1 and 4-HNE were analyzed using immunostaining to establish the effect of Immp2L mutation on oxidative stress in the kidney. SOD-1 immunostaining was considered positive when inside tubular-epithelial cells. Young mutant mice had a significantly higher expression of SOD-1 than the young wild type $(\mathrm{p}=0.037)$. Young mutants also had higher expression of SOD-1 compared to old mutants $(p=0.039)$ and old controls $(p=0.015)$. SOD-1 expression in old mutants was not different from that in wild type animals (Figure 3A, and Figures 4A to 4D). Interestingly, SOD-1 mRNA did not change in young mice, suggesting posttranscriptional regulation of SOD-1 protein in young mutant mice (Figure 5).
4-HNE immunostaining was considered positive when three or more cells were positive in the same tubule. Old mutants had significantly higher 4-HNE than wild types $(p=0.024)$. Staining for $4-H N E$ was similar in young mutants compared to young age-matched controls (Figure 3B, and Figures 4E to $4 \mathrm{H}$ ).

Macrophage and monocyte infiltration was determined by counting the number of CD68-positive cells in the kidney. The number of macrophages/monocytes was similar in young mice (young wild type: $4 \pm 1.4$ cells per field versus young mutant mice: $3.75 \pm 1.25$ cells per field). Old mutants had significantly more inflammatory cells than age-matched controls (old wild-type: $10 \pm 2.5$; old mutants: $13.5 \pm 2.65 ; \mathrm{p}=0.012$ ) (Figure 3C, and Figures $4 \mathrm{I}$ to $4 \mathrm{~L}$ ).

Apoptotic cells were determined by using TdT staining. Young mutant mice had a tendency to exhibit a higher number of apoptotic cells than aged matched controls (young mutants: $27 \pm 7$ cells per field versus
Superoxide dismutase 1 expression
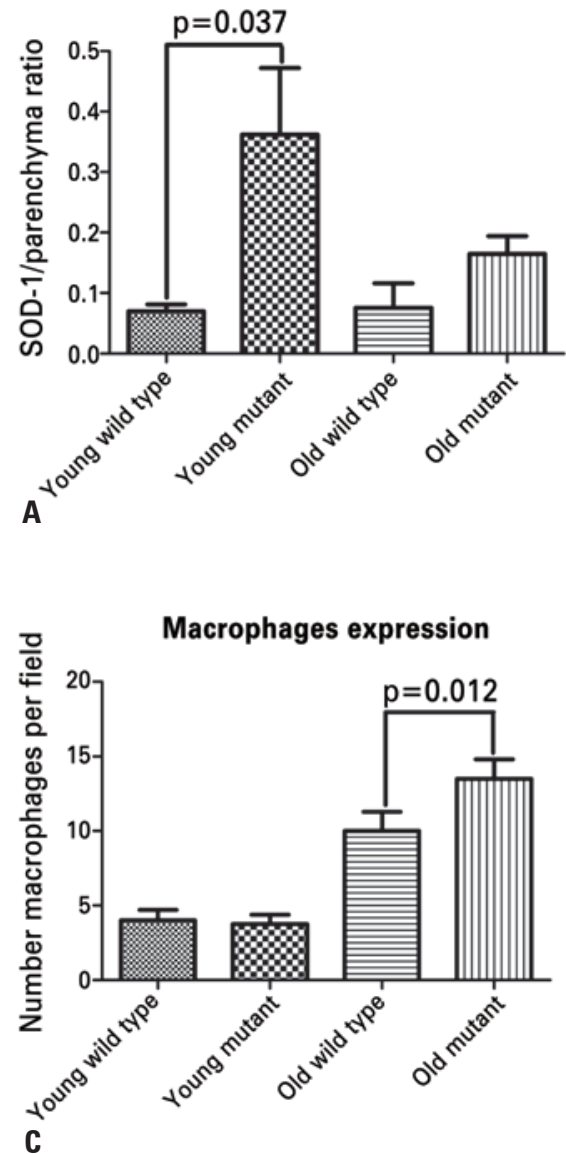

\section{4-hydroxi-2-noneal}
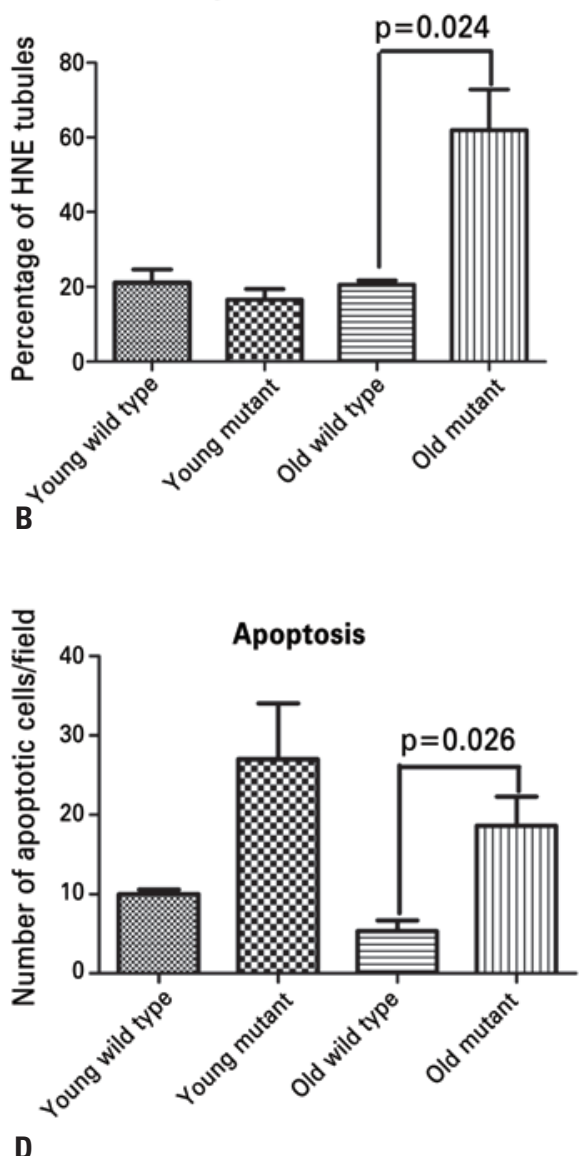

Figure 3. Analysis of superoxide dismutase 1 (SOD-1), 4-hydroxynonenal (4-HNE), CD68-positive cells, and apoptotic cells in the kidney of Immpl2 mice and wild type controls. Panel A displays SOD-1 expression in kidney of Immpl2 mice. Young mutants had significantly higher SOD-1 than aged matched controls, while no difference was found in old animals. 4-HNE had greater expression in kidneys from old mutants than in age-matched controls (B). Macrophage expression (C) was also higher in old mutants compared to old controls. Apoptosis was significantly higher in old mutants than in controls 


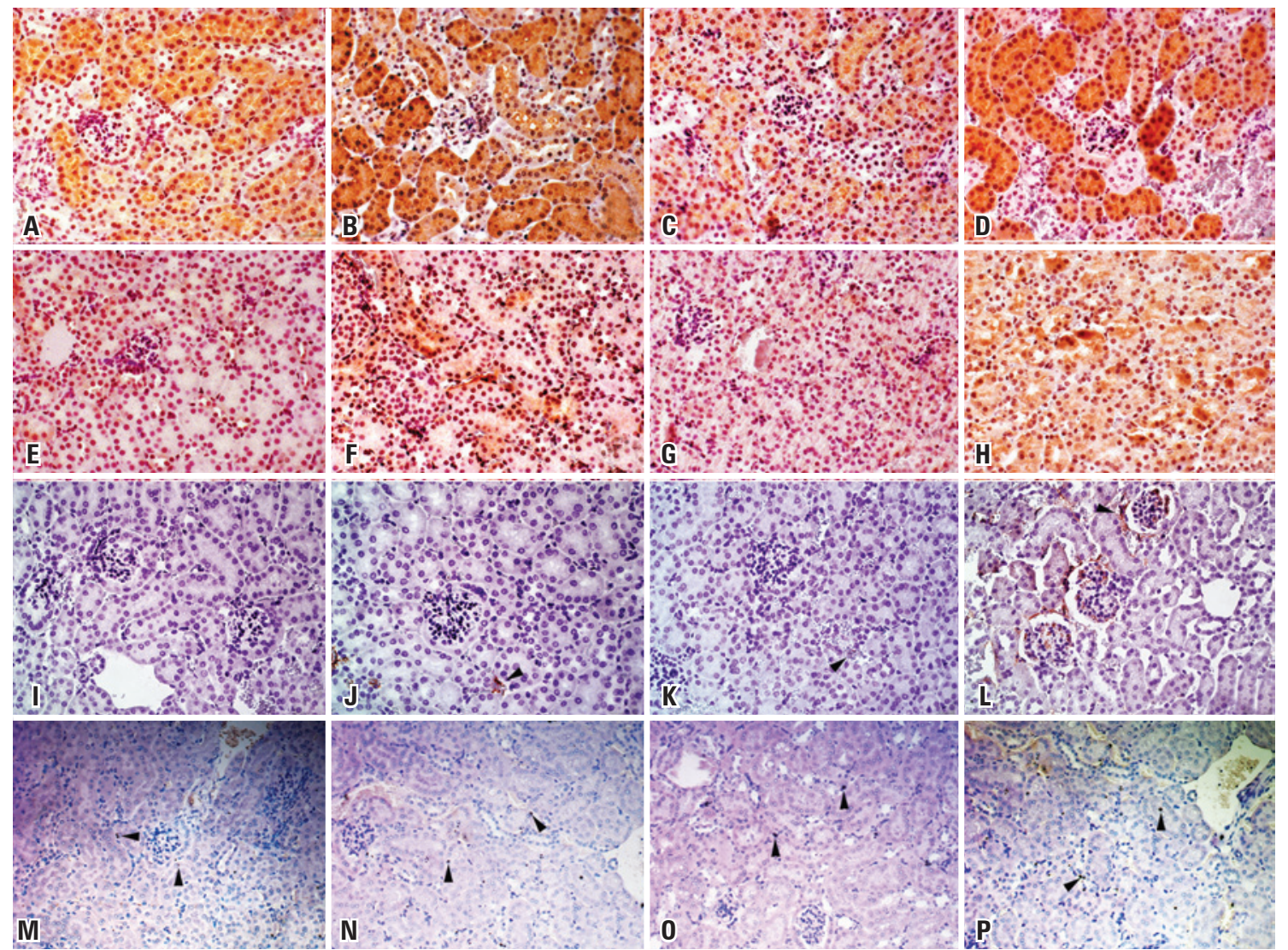

Figure 4. Representative pictures of superoxide dismutase 1, 4-hydroxynonenal, CD68-positive cells, and the apoptotic cells in the kidney of Immpl2 mice. Panels A to $D$ represent young wild type, young mutant, old wild type, and old mutant expression of superoxide dismutase-1, respectively. Young mutants exhibited a higher expression of superoxide dismutase 1 than age-matched controls. Panels $\mathrm{E}$ to $\mathrm{H}$ correspond to 4-hydroxynonenal, showing the higher expression in mutants, especially in old ones. Panels I to L correspond to the macrophage/monocyte infiltration in young wild type, young mutant old wild type, and old controls, respectively. Brown staining pointed out by the arrows represents the macrophages. Panels $\mathrm{M}$ to $\mathrm{P}$ demonstrate the apoptotic cells in young wild type, young mutant, old wild type, and old mutants, respectively. The black staining in the nuclei pointed out by arrows shows the positive cells. Old mutants had a higher number of black nuclei compared to wild type old animals. 20x magnification

young controls: $10 \pm 0.57$ cells per field; $p=0.072$ ). However old mutants had significantly higher number of apoptotic cells compared to old wild type animals (old mutants: $18.67 \pm 3.66$ cells per field versus old wild type mice: $5.33 \pm 1.33$ cells per field; $\mathrm{p}=0.026$ ) (Figure 3D, and Figures 4M to 4P).

Profibrotic genes were evaluated by real-time PCR (RT-PCR) (Figure 5). In mutant animals, MMP-9 mRNA was 2.5 -fold higher than in the old wild type and the young animals. EPO gene was also upregulated six-fold. However, TGF- $\beta$ was only 1.4-fold higher in mutant mice than in old wild type animals (Figure 5).

Since most of the architectural abnormalities were found in the old mutants, we analyzed the plasma creatinine in these animals. Young mutant mice had significantly higher serum creatinine levels than the young wild type animals $(\mathrm{p}<0.0001)$. Young mutants also had higher serum creatinine compared to old mutants $(p=0.008)$ and old controls $(p=0.0001)$.

\section{DISCUSSION}

Interstitial fibrosis is the common feature of most diseases progressing to chronic kidney failure. Human kidney biopsy studies showed a correlation between interstitial fibrosis and unfavorable prognosis. ${ }^{(10,11)}$ Kidney fibrosis in diabetes, aging and ischemia/ reperfusion injury has been linked to excessive production of ROS, which is considered the major pathogenic pathway in these disorders. ${ }^{(3)}$ The ROS excess is linked to alterations in mitochondrial metabolism leading to cell damage. The kidney is particularly affected by the aging process: age increases glomerulosclerosis and interstitial fibrosis. ${ }^{(12)}$ Agingassociated changes at the cellular level include increased number of mutations in nuclear and mitochondrial DNA, lipofuscin and advanced glycation end products (AGE), increased oxidative stress and consequent increased apoptosis. ${ }^{(13)}$ Ischemia/reperfusion injury in the kidney produces excess of ROS beyond this organ's 


\section{Superoxide dismutase-1}

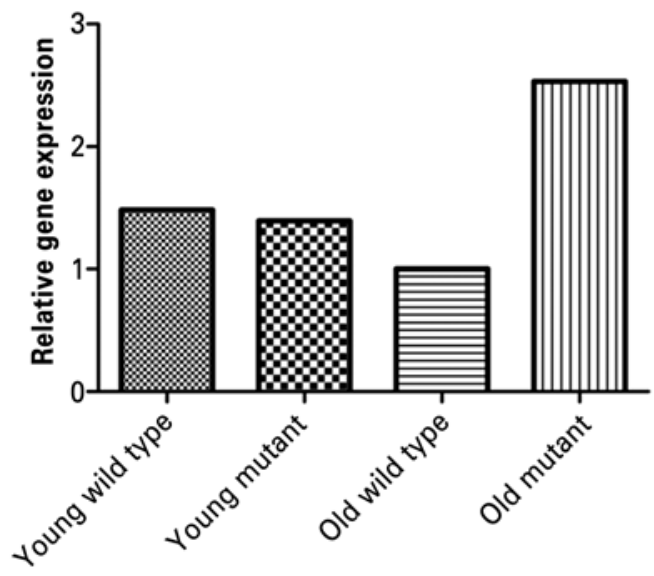

Metalloproteinase-9

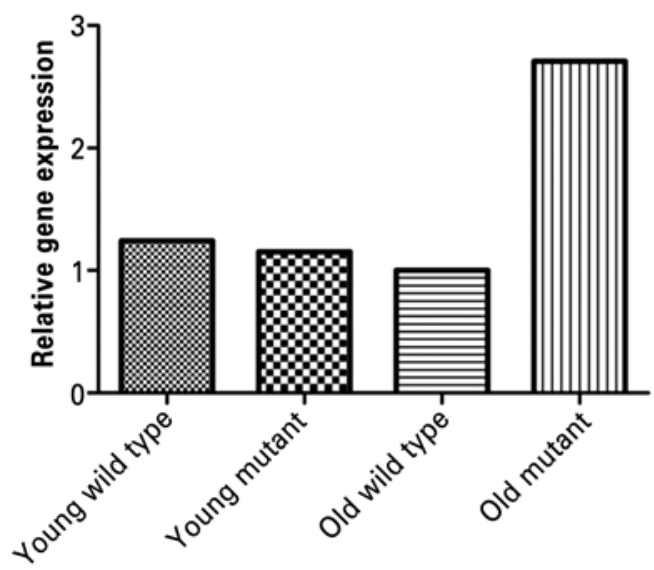

Erythropoietin

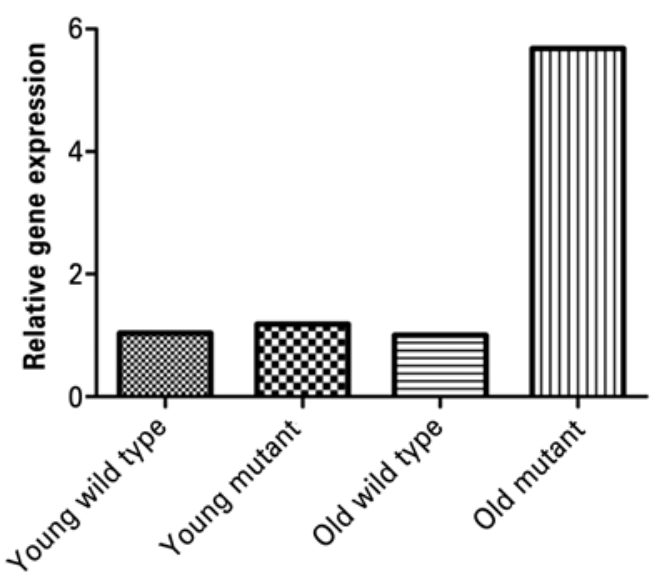

TGF-beta

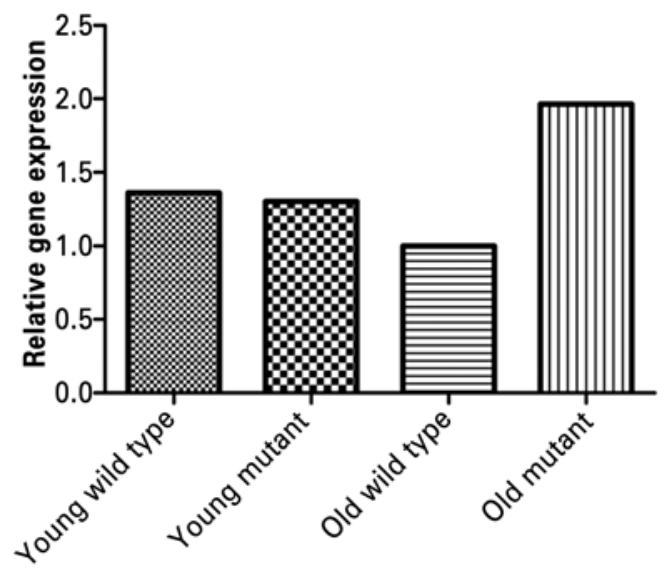

Figure 5. Analyses of renal superoxide dismutase 1, erythropoietin, metalloproteinase- 9 and transforming growth factor beta (TGF- $\beta$ ) gene expression in the kidney of Immpl2 mice and wild type controls. Renal superoxide dismutase 1, erythropoietin, metalloproteinase- 9 and TGF- $\beta$ mRNA were significantly higher in old mutants compared to old wild type mice

scavenging capacity, causing cell damage; excess of ROS has been associated with chronic allograft nephropathy after kidney transplantation. ${ }^{(8)} \mathrm{A}$ common feature of all these conditions is the ROS overproduction, which leads to renal fibrosis and progressive chronic disease. Oxidative stress and inflammation go hand-in-hand in many tissues. Oxidative stress induces the production of inflammatory cytokines that will, in turn, induce free radical production. One specific aldehyde is 4-HNE, that is increasingly recognized as a mediator and marker of cellular dysfunction. In the Immp2L mouse model, the overproduction of extracellular matrix, glomerulosclerosis, apoptotic cells, and upregulation of pro-inflammatory genes may be related to the superoxide excess and show an accelerated aging process with function loss.
The Immp2L mutant mice have been shown to have a deficiency in the amount of CYC1 in various tissues, including the kidney. The mitochondria from these mice also showed excess levels of ATP and superoxide ion. The mitochondrial protein, CYC1, in the kidney was shown to have higher molecular weight than those in controls. ${ }^{(7)}$ We found that compared to aged-matched controls, young mutants had a higher glomerulosclerosis score, tubular cast formation, and tubular atrophy. Analyses of extracellular matrix deposition, as reflected by deposition of total collagen and type IV collagen, were consistently higher in the young mutants than in aged-matched control animals. Old mutant animals had a similar glomerulosclerosis score and tubular atrophy as the aged-matched animals. However old mutant mice had significantly higher total 
collagen deposition and type IV collagen deposition than age-matched controls suggesting an increased extracellular matrix deposition, showing a fibrotic mechanism ongoing in the kidney. Macrophages/ monocytes were more abundant in old mutant mice compared to age-matched controls showing a possible influx of inflammatory cells to the kidney tissue during the fibrotic process. Also, old mutants had higher creatinine levels then age-matched controls. Together, these findings suggest that mutation in mitochondrial Immp2L may alter the normal architecture of the kidney by increasing the deposition of extracellular matrix.

Compared to age-matched controls, young mutant animals had significantly higher SOD-1 expression, the most common superoxide scavenger enzyme in the kidney. Higher expression of this enzyme may represent a compensatory mechanism to overcome an increased superoxide production. ${ }^{(14,15)}$ In other models with increased ROS generation, the SOD expression seems to vary. Fujita et al., ${ }^{(3)}$ in two diabetic mice models (KK/Ta-Akita and C57BL/6-Akita), reported different susceptibility to diabetic nephropathy despite comparable hyperglycemia levels. KK/Ta-Akita mice developed albuminuria as the mice aged and presented with downregulation of SOD-1 and SOD-3, while C57BL/6-Akita had normal SOD expression and were more resistant to diabetic nephropathy. When KK/ Ta-Akita mice were treated with a SOD mimetic, an attenuation of diabetic nephropathy was observed. Therefore, we may assume that the higher SOD-1 expression in young mutant mice, compared to the agematched controls, is a protective mechanism, although not fully successful. The amount of SOD-1 did not differ between old mutants and the age-matched control animals. However, old mutants had upregulation of SOD-1 gene expression, possibly reflecting an attempt to scavenge the superoxide excess. These findings are in accordance with those of Dobashi et al., ${ }^{(14)}$ showing that the expression of antioxidant genes, such as SOD-1, is not directly coordinated with the respective protein expression. The loss of antioxidant enzymes may be a contributing factor towards renal damage as a result of the aging process.

In addition to an upregulation of SOD-1, old mutants had an increased 4-HNE protein in the kidney showing the breakdown of the superoxide scavenger mechanism leading to tissue damage. These findings suggest that while young animals produce more SOD-1, the tissue is only partially protected against renal injury.
Epithelial-to-mesenchymal transition defines a phenotypic transformation in epithelial cells. ${ }^{(2,10,16)}$ After injury, epithelial cells lose their epithelial markers and start expressing some mesenchymal markers such as S100A4. Old mutant animals had significantly higher presence of S100A4 than their aged matched controls, while young mutants did not show this marker in the tubular epithelial cells. These observations suggest that during chronic exposure to superoxide, kidney cells lose their differentiation and start expressing fibroblast markers that represent the epithelial-mesenchymal transition. This transformation may be one of the sources of the overproduction of extracellular matrix in the kidney of old mutants represented as increased collagen type IV deposition. MMP-9 gene expression was also upregulated in old Immp2L mutants in an attempt to enzymatic digest the collagen deposition. These data suggest that mitochondrial Immp2L mutation leads to the epithelial-to-mesenchymal transition and fibrosis progression in the kidney.

Old mutant animals had a significantly higher number of apoptotic cells than aged matched controls, suggesting that Immp2L signaling may attenuate cell apoptosis. In the animal model of renal ischemia/ reperfusion injury, administration of an antioxidant enzyme mimetic, MnTMPyP, attenuated the number of apoptotic cells ${ }^{(8)}$ suggesting that oxidative damage is associated with an increase in cell apoptosis. The anti-apoptotic effects of exogenous EPO have been reported by several investigators. ${ }^{(17-21)}$ Recombinant human EPO (rhEPO) has multiple paracrine and autocrine functions that coordinate the local responses to injury attenuating both the primary (apoptotic) and the secondary (inflammatory) causes of cell death. ${ }^{(22)}$ Moreover, clinical studies have reported that rhEPO reduces oxidative stress. ${ }^{(23)}$ It can be speculated that in our model, the increase in EPO expression in older mutant mice was due to a compensatory response to renal damage.

\section{CONCLUSIONS}

A mutation in the Immp2L gene associated with increased levels of mitochondrial superoxide attenuated the antioxidant defense markers, and increased kidney interstitial extracellular matrix deposition and glomerulosclerosis with loss of function. We suggest that Immp2L is protective against the development of renal fibrosis. Moreover, the Immp2L mutant mouse model may be useful for further investigations of the role of superoxide in the development of kidney fibrosis and the aging process. 


\section{Author contribution}

Nadia Karina Guimarães-Souza designed the study, performed the experiments, wrote and edited the manuscript. Liliya Marsovna Yamaleyeva performed the experiments, wrote and edited the manuscript. Ana Claudia Mallet performed the experiments. Baisong Lu provided Immp2L mutant mice. Colin E. Bishop provided Immp2L mutant mice. Karl Erik Andersson designed the study, edited the manuscript.

\section{REFERENCES}

1. Wynn TA. Cellular and molecular mechanisms of fibrosis. J Pathol. 2008; 214(2):199-210. Review.

2. Djamali A, Reese S, Yracheta J, Oberley T, Hullett D, Becker B. Epithelial-tomesenchymal transition and oxidative stress in chronic allograft nephropathy. Am J Transplant. 2005:5(3):500-9.

3. Fujita H, Fujishima H, Chida S, Takahashi K, Qi Z, Kanetsuna Y, et al. Reduction of renal superoxide dismutase in progressive diabetic nephropathy. J Am Soc Nephrol. 2009;20(6):1303-13.

4. Touyz RM. Reactive oxygen species, vascular oxidative stress, and redox signaling in hypertension: what is the clinical significance? Hypertension. 2004;44(3):248-52. Review.

5. Sies H. Oxidative stress: oxidants and antioxidants. Exp Physiol. 1997;82(2):291-5. Review.

6. Mattson MP. Roles of the lipid peroxidation product 4-hydroxynonenal in obesity, the metabolic syndrome, and associated vascular and neurodegenerative disorders. Exp Gerontol. 2009;44(10):625-33. Review.

7. Lu B, Poirier C, Gaspar T, Gratzke C, Harrison W, Busija D, et al. A mutation in the inner mitochondrial membrane peptidase 2-like gene (Immp2L) affects mitochondrial function and impairs fertility in mice. Biol Reprod. 2008;78(4):601-10.

8. Kim J, Seok YM, Jung KJ, Park KM. Reactive oxygen species/oxidative stress contributes to progression of kidney fibrosis following transient ischemic injury in mice. Am J Physiol Renal Physiol. 2009;297(2):F461-70.

9. Jaimes EA, Galceran JM, Raij L. Angiotensin II induces superoxide anion production by mesangial cells. Kidney Int. 1998;54(3):775-84.

10. Bedi S, Vidyasagar A, Djamali A. Epithelial-to-mesenchymal transition and chronic allograft tubulointerstitial fibrosis. Transplant Rev (Orlando). 2008;22(1):1-5. Review.
11. Mackensen-Haen S, Bohle A, Christensen J, Wehrmann M, Kendziorra H, Kokot $\mathrm{F}$. The consequences for renal function of widening of the interstitium and changes in the tubular epithelium of the renal cortex and outer medulla in various renal diseases. Clin Nephrol. 1992;37(2):70-7.

12. Baylis $C$. Changes in renal hemodynamics and structure in the aging kidney; sexual dimorphism and the nitric oxide system. Exp Gerontol. 2005;40(4):271-8. Review.

13. Percy CJ, Power D, Gobe GC. Renal ageing: changes in the cellular mechanism of energy metabolism and oxidant handling. Nephrology (Carlton). 2008;13(2):147-52. Review.

14. Dobashi K, Ghosh B, Orak JK, Singh I, Singh AK. Kidney ischemia-reperfusion: modulation of antioxidant defenses. Mol Cell Biochem. 2000;205(1-2):1-11.

15. Ghosh S, Khazaei M, Moien-Afshari F, Ang LS, Granville DJ, Verchere CB, et al. Moderate exercise attenuates caspase-3 activity, oxidative stress, and inhibits progression of diabetic renal disease in $\mathrm{db} / \mathrm{db}$ mice. Am J Physiol Renal Physiol. 2009;296(4):F700-8.

16. Iwano M, Plieth D, Danoff TM, Xue C, Okada H, Neilson EG. Evidence that fibroblasts derive from epithelium during tissue fibrosis. J Clin Invest. 2002; 110(3):341-50

17. Park SH, Choi MJ, Song IK, Choi SY, Nam JO, Kim CD, et al. Erythropoietin decreases renal fibrosis in mice with ureteral obstruction: role of inhibiting TGF-beta-induced epithelial-to-mesenchymal transition. J Am Soc Nephrol. 2007;18(5):1497-507.

18. Hamed S, Ullmann Y, Masoud M, Hellou E, Khamaysi Z, Teot L. Topical erythropoietin promotes wound repair in diabetic rats. J Invest Dermatol. 2010;130(1):287-94.

19. Shimoda M, Sawada T, Iwasaki Y, Mori S, Kijima H, Okada T, et al. Erythropoietin strongly protects the liver from ischemia-reperfusion injury in a pig model. Hepatogastroenterology. 2009;56(90):470-5.

20. Timmer SA, De Boer K, Knaapen P, Götte MJ, Van Rossum AC. The potentia role of erythropoietin in chronic heart failure: from the correction of anemia to improved perfusion and reduced apoptosis? J Card Fail. 2009;15(4):353-61. Review.

21. Song YR, You SJ, Lee YM, Chin HJ, Chae DW, Oh YK, et al. Activation of hypoxia-inducible factor attenuates renal injury in rat remnant kidney. Nephrol Dial Transplant. 2010;25(1):77-85.

22. Calvillo L, Latini R, Kajstura J, Leri A, Anversa P, Ghezzi P, et al. Recombinant human erythropoietin protects the myocardium from ischemia-reperfusion injury and promotes beneficial remodeling. Proc Natl Acad Sci U S A. 2003; 100(8):4802-6

23. Kumral A, Gonenc S, Acikgoz 0, Sonmez A, Genc K, Yilmaz 0, et al Erythropoietin increases glutathione peroxidase enzyme activity and decreases lipid peroxidation levels in hypoxic-ischemic brain injury in neonatal rats. Biol Neonate. 2005:87(1):15-8. 